\title{
Bioprospecting thermostable cellulosomes for efficient biofuel production from lignocellulosic biomass
}

\author{
Richa Arora ${ }^{1,2}$, Shuvashish Behera ${ }^{1}$, Nilesh Kumar Sharma ${ }^{1,2}$ and Sachin Kumar ${ }^{{ }^{*}}$ (])
}

\begin{abstract}
The adverse climatic conditions due to continuous use of fossil-derived fuels are the driving factors for the development of renewable sources of energy. Current biofuel research focuses mainly on lignocellulosic biomass (LCB) such as agricultural, industrial and municipal solid wastes due to their abundance and renewability. Although many mesophilic cellulolytic microorganisms have been reported, efficient and economical bioconversion to simple sugars is still a challenge. Thermostable cellulolytic enzymes play an indispensible role in degradation of the complex polymeric structure of LCB into fermentable sugar stream due to their higher flexibility with respect to process configurations and better specific activity than the mesophilic enzymes. In some anaerobic thermophilic/thermotolerant microorganisms, few cellulases are organized as unique multifunctional enzyme complex, called the cellulosome. The use of cellulosomal multienzyme complexes for saccharification seems to be a promising and cost-effective alternative for complete breakdown of cellulosic biomass. This paper aims to explore and review the important findings in cellulosomics and forward the path for new cutting-edge opportunities in the success of biorefineries. Herein, we summarize the protein structure, regulatory mechanisms and their expression in the host cells. Furthermore, we discuss the recent advances in specific strategies used to design new multifunctional cellulosomal enzymes, which can function as lignocellulosic biocatalysts and evaluate the roadblocks in the yield and stability of such designer thermozymes with overall progress in lignocellulose-based biorefinery.
\end{abstract}

Keywords: Cellulose hydrolysis, Cellulosomes, Scaffoldin, Nanomachines, Synergy

\section{Background}

The progressive rise in energy crisis with the depletion of fossil-derived fuels has led to the search for other substitutive sources of energy, which are renewable, sustainable, economical, environment friendly and convenient. Energy from renewable biomass can be exploited as a potential alternative to fossil-derived fuels (Arora et al. 2015).

Biofuel production by biological conversion of lignocellulose is rising as a promising strategy, which can be considered as cost-effective, environmentally sustainable

\footnotetext{
*Correspondence: sachin.biotech@gmail.com

${ }^{1}$ Biochemical Conversion Division, Sardar Swaran Singh National Institute of Bio-Energy (Formerly Sardar Swaran Singh National Institute of Renewable Energy), Kapurthala, Punjab, India

Full list of author information is available at the end of the article
}

and alternative to non-renewables (Behera et al. 2014). The biochemical conversion of lignocellulosic biomass (LCB) comprises three main steps, viz. pretreatment, saccharification and fermentation. Many researchers have reported the production of biofuels using LCB (Kumar et al. 2010; Arora et al. 2014). However, despite the extensive research on bioconversion of cellulosic material, there are certain technological barriers. One of the major challenges is the efficient enzymatic hydrolysis of recalcitrant LCB (Stern et al. 2014). The breakdown of cellulose requires very high synergistic interactions among the cellulose-degrading enzymes (Behera et al. 2013). Commercial extraction of fermentable sugars from lignocellulosic material can be accomplished by the use of cellulases. However, the production of cellulases at the industrial level remains very challenging due to high cost. The high cost of cellulase production is attributed

\section{Springer}

(c) 2015 Arora et al. This article is distributed under the terms of the Creative Commons Attribution 4.0 International License (http://creativecommons.org/licenses/by/4.0/), which permits unrestricted use, distribution, and reproduction in any medium, provided you give appropriate credit to the original author(s) and the source, provide a link to the Creative Commons license, and indicate if changes were made. 
to several factors including the use of costly inducers such as cellulose and lactose and controlling the process by the dynamics of the induction-repression mode (Sukumaran et al. 2005). Appropriate amount of glucose is required in the medium for meeting the physiological needs of the cell and prevention of feedback inhibition of cellulases, which further requires expensive monitoring systems (Ju and Afolabi 1999). Another challenge for cellulase production is the development of bioprocess with cost-effective titer of cellulase using cheap media (Shahriarinour et al. 2011). Moreover, the problems with many cellulase-producing microorganisms are requirement of special culturing conditions and low product yield with secretion of some unwanted products (Lambertz et al. 2014). Further, saccharification with the conventional mesophilic microorganisms remains challenging due to high enzyme loading to meet the industrial needs, long incubation period and lesser mass transfer at lower temperatures (Stern et al. 2014; Rollin et al. 2011).

Recent studies mainly focus on the use of thermophilic/ thermotolerant microorganisms and thermozymes due to their cost-effective catalytic process (Arora et al. 2014). Thermozymes are reported to be more stable at various environmental stresses with higher specific activities, longer half-lives, substrate solubility and more diffusion rates, thereby aiding in the process economy (Anbar et al. 2012; Wu and Arnold 2013). Mostly, anaerobic thermophilic microorganisms possess highly efficient enzymes that are structured in multienzyme complexes known as cellulosomes (Fontes and Gilbert 2010). Cellulosomal enzymes work synergistically without any inducer requirement and show very high level of regulation without being repressed by the product (Yamada et al. 2013).

Herein, the architecture and assembly of various subunits of cellulosomes along with gene regulation are discussed. This would provide a comprehensive update of the physiology of cellulosome-producing microorganisms. Furthermore, specific strategies in the construction of designer cellulosomes are discussed. The aim of this review article is to explore the latest advances in cellulosomics and their indispensible role in the biomassbased refineries.

\section{Thermostable cellulase family}

The tightly packed structures of cellulose and its crosslinking with hemicellulose and lignin make the process of cellulose degradation very slow and costly (Behera et al. 2014). Hydrogen bonding between the chains makes the structure of lignocellulosic biomass very rigid and recalcitrant (Yamada et al. 2013). Thermostable cellulases are characterized by hydrophobic protein core and polarity at the surface; compact structure with lesser internal voids; higher content of proline and lesser content of asparagines, glutamine, methionine and cysteine; increased level of $\mathrm{H}$-bonding, isoelectric points and salt bridges (Taylor and Vaisman 2010; Li et al. 2011).

The cellulolytic enzymes are categorized into three main groups: endoglucanases, exoglucanases and $\beta$-glucosidases with scientific nomenclature as (E.C. 3.2.1.4), (E.C. 3.2.1.176) and (E.C. 3.2.1.21), respectively (Garvey et al. 2013; Juturu and Wu 2014). The cleavage of internal bonds of the cellulose chain is catalyzed by endoglucanases (endo-1,4- $\beta$-glucanases) that catalyze randomly, while the ends of the chain are cleaved by the exoglucanases (exo-1,4- $\beta$-glucanases), which release cellobiose. Further, the breakdown of bonds of cello-oligosaccharides and cellobiose is catalyzed by $\beta$-glucosidases which release the glucose units (Kumar et al. 2008; Prasetyo et al. 2011).

Cellulase activity is mostly found in Clostridiales (anaerobic) and Actinomycetales (aerobic), respectively. Both aerobic and anaerobic microorganisms have different modes of action as discussed below.

\section{Cellulose hydrolysis by aerobic microorganisms}

Aerobic microorganisms do not adhere to cellulose; instead, they secrete extracellular enzymes which initiate the hydrolysis resulting in the formation of cellodextrins. These cellodextrins are then transferred inside the cell where they are oxidized to carbon dioxide and water (Lynd et al. 2002; Horn et al. 2012).

\section{Cellulose hydrolysis by anaerobic microorganisms}

Anaerobic bacteria adhere to the cellulose fibers by a unique structure known as cellulosome and then release cellulolytic enzymes which cause hydrolysis of cellulose to cellodextrins. Adhesion to cellulose can also occur via fimbriae, pili or carbohydrate epitopes of bacterial glycocalyx (Sadhu and Maiti 2013). Some of the hydrolyzed molecules enter into the cell where they undergo fermentation. The products of fermentation are used for cross-feeding non-cellulolytic bacterium. Other cellodextrin molecules formed by hydrolysis are effluxed out of the cells and are used by other non-adherent cellulolytic bacterium. Clostridium thermocellum is a highly efficient bacterium known for degradation of cellulose with the help of its cellulosome (Lamed et al. 1983).

\section{Cellulosomes: futuristic approach for cellulose degradation}

Extremely efficient nanomachines, known as cellulosomes, are produced by many anaerobic and ruminal microorganisms to degrade the complex polysaccharides of plant cell wall and crystalline cellulose (Hyeon et al. 2013). Such supramolecular complexes were first discovered in thermophilic bacterium $C$. thermocellum. 
Cellulosomes are multienzyme complexes held together by the high affinity of interaction among its subunits (Gefen et al. 2012). Major functions of cellulosomes include a high rate of substrate uptake, tight and specific interaction with the substrate, synergistic activity and processivity of the enzymes (Desvaux 2005). Cellulosomic complexes have been investigated in many other species including Clostridium acetobutylicum, C. josui, $C$. cellulovorans, C. papyrosolvens, C. cellulolyticum, C. clariflavum, Bacteroides cellulosolvens, Ruminococcus albus, R. flavefaciens and Acetivibrio cellulolyticus (Cho et al. 2010; Hemme et al. 2010; Karpol et al. 2013; Smith and Bayer 2013; Ichikawa et al. 2014).

The complex architecture of cellulosomes enables various enzymes attached to act in a coordinated way and increase the efficiency of the enzymes through synergistic interactions (Morais et al. 2010; Chanal et al. 2011). The enzymes in the cellulosomes are positioned in close proximity, so that the whole system can act synergistically for depolymerisation of cellulose (Hyeon et al. 2011; Mazzoli 2012).

The numbers of cellulosomal enzymes vary from species to species in different microorganisms with different catalytic mechanisms and substrate specificities (Morais et al. 2010; Bayer et al. 2008; Doi 2008). In case of polycellulosomes, more than 100 subunits have been reported (Bras et al. 2012). The assembly of various cellulosomal proteins has been exclusively studied in C. thermocellum (Belaich et al. 1997; Bayer et al. 2004; Ding et al. 2012).

The hydrolysis of the polymers of plant cell wall depends upon the extent of interaction between various subunits of cellulosomes (Tamaru et al. 2010). The synergistic interaction between various subunits of cellulosomal enzymes with the substrate results in the formation of cellobiose from cellulose, thereby leading to efficient degradation of complex biomass (Fontes and Gilbert 2010).

\section{Cellulosome structure and assembly}

Cellulosomes are well-organized nanomachines playing an elementary function in the breakdown of complex polymers of cell wall. The cellulosome is composed of both structural and catalytic subunits consisting of scaffoldin, cohesion and dockerin, carbohydrate-binding module (CBM), surface layer homology domain and catalytic enzymes (Mazzoli et al. 2012). The assembly of different components of cellulosomes on the surface of the cell is shown in Fig. 1. These subunits are held together by highly specific type I and type II interactions between the cohesins and the dockerins (Bayer et al. 2004). Type I interactions are the interactions between dockerins and scaffoldin cohesions. In addition to this, scaffoldin dockerins interact with cohesins on the cell surface. Such interactions are termed as type II interactions (Smith and Bayer 2013). Different components of cellulosomes are discussed below.

\section{Scaffoldin}

Scaffoldin subunit is an anchoring protein which has a dual function of incorporating various enzymatic subunits through the tight interactions between the cohesin and dockerin moieties and binding to the substrate with the help of carbohydrate-binding module (CBM) (Mazzoli et al. 2012; Himmel et al. 2010). In some microorganisms, multiple scaffoldins have been reported where a primary scaffoldin is anchored by a secondary scaffoldin subunit for amplifying the catalytic moieties onto the surface (Doi 2008).

\section{Cohesin and dockerin}

The particular sequence of cohesin and dockerin represents the signature sequences of the cellulosomal protein (Shoham et al. 1999). The assembly of whole cellulosomal subunit depends upon the affinity of interaction between dockerin domains having duplicated sequences and cohesin domains containing repeated sequences, as this interaction provides the most favorable arrangement for the enzymes to act efficiently on the substrate (Jeon et al. 2012). The heterogenous nature of cellulosomes is due to the variability in the interaction of cohesin-dockerin moieties with difference in the amount of cohesin repeats, nature of enzymes bound to the scaffolding protein and species-specific variations (Bomble et al. 2011; Koukiekolo et al. 2005; Doi and Kosugi 2004; Fierobe et al. 2005).

Dockerins are symmetrical molecules usually present at the C-terminus with two duplicated segments of approximately 22 amino acids (Fontes and Gilbert 2010). Calcium plays a very critical role in the functioning and stability of dockerin molecules (Karpol et al. 2013). Each of the duplicated segments contains calcium-binding residues (asparagines or aspartate) which are highly conserved in the first 12 residues (Fontes and Gilbert 2010). The tight interaction between dockerin and cohesin is dependent upon calcium, which binds with the dockerin and brings about folding and conformational changes (Adams et al. 2005). Chen et al. (2014) investigated the nuclear magnetic resonance (NMR)-derived structure of dockerin module from Cel48S of C. thermocellum and concluded that the dockerin moiety does not undergo structural alterations induced by cohesin, but assumes a calcium-dependent cohesin-primed conformation.

\section{Carbohydrate-binding module}

A carbohydrate-binding module (CBM), belonging to family $3 \mathrm{a}$, is present on the non-catalytic scaffolding protein 


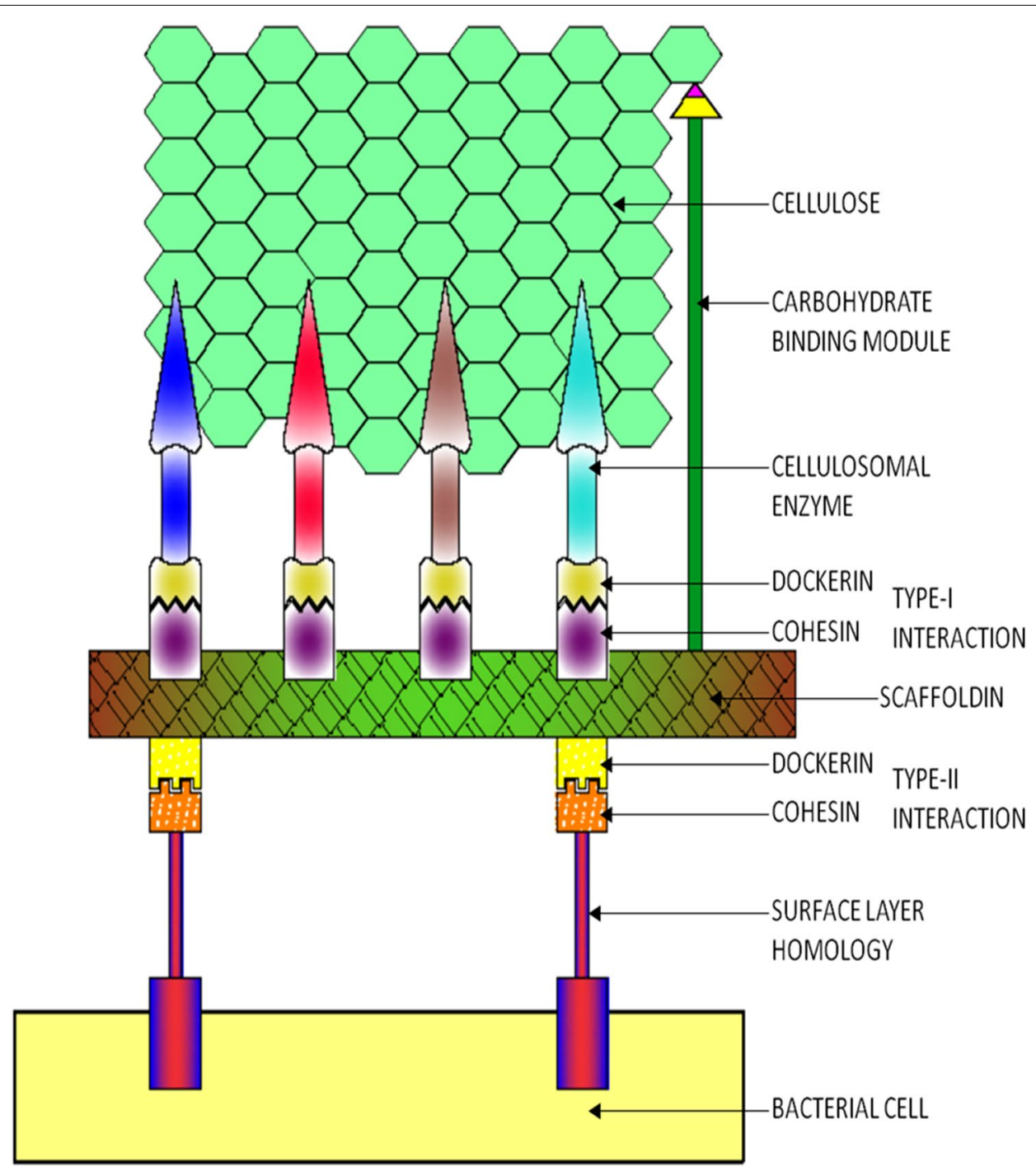

Fig. 1 A cellulosome on the bacterial cell

and aids in the recognition, attachment and effective degradation of cellulose by disrupting the crystal surface at the solid-liquid interface (Ichikawa et al. 2014; Lavan et al. 2009). This domain is non-catalytic by nature, but it plays a significant role in the enzymatic activity of the cellulosomal enzymes. The binding of CBM with the cellulosic substrate nullifies the hydrogen bonding and brings the cellulosomal enzymes close to the cellulose, thus making the breakdown more efficient compared to the free enzymes (Lynd et al. 2002; Tamaru et al. 2000; Caspi et al. 2008).

CBMs have been categorized into three different categories according to their substrate range, viz. type A, type $B$ and type $C$ which bind to insoluble polysaccharide surfaces, soluble glycan chains and smaller saccharides, respectively. Several researchers have reported various modifications in the activity and composition of various subunits of cellulosomes to increase the interaction between the target substrate with one or more CBMs (Elkins et al. 2010; Raman et al. 2009). The nature of amino acids present at the CBM determines the specificity of binding with the substrate. For example, the presence of polar and aromatic amino acids in CBM (of CBM3a family) of CbpA protein allows the preferential binding of $C$. cellulovorans to crystalline cellulose rather than amorphous cellulose (Boraston et al. 2004; Yaniv et al. 2012).

\section{Surface layer homology domain}

The anchoring of cellulosome to the cell surface is made by surface layer homology (SLH) domain through 
non-covalent interactions (Bayer et al. 2008; Tamaru et al. 2000). The SLH forms a protein layer outside of the cell wall, which is highly conserved in the cellulosomal bacteria (Desvaux et al. 2006). The scaffolding protein CbpA contains repeated domains with bacterial SLH homology-related anchoring functions in C. cellulovorans (Tamaru et al. 2000).

\section{Cellulosomal enzymes}

The catalytic domains, i.e., cellulosomal enzymes are assembled by their dockerin moieties linked to cohesin domains of scaffoldin by calcium dependent interactions (Cho et al. 2010; Ding et al. 2008). Localization of broad substrate range enzymes and their close proximity for efficient formation of enzyme-substrate complex are the significant factors for increasing the efficiency of the cellulosomes. Cellulosomes are known to have better enzymatic activity as compared to free enzymes because of the close proximity of various cellulases which act synergistically (Blanchette et al. 2012; Krauss et al. 2012; You et al. 2012a). However, the mechanism of protein assembly and organization of various catalytic enzymes in the cellulosomes is partially known (Wilson 2011). The complex architecture of the cellulosomal complex helps to minimize the diffusion of several smaller saccharides and facilitate their easy and fast uptake by glycosidases for complete hydrolysis (Vodovnik and Logar 2010). The cellulosomal microorganisms can vary the composition of various catalytic subunits according to the substrate available to them (Cho et al. 2010; Blouzard et al. 2010; Tsai et al. 2010). A variety of cellulosomes with variable composition can be assembled on a single species with various enzymes bound to the scaffolding protein (Bomble et al. 2011).

\section{Cellulosomal gene clusters and their regulation}

The mechanism of gene expression has been widely studied in C. thermocellum. The genes encoding the cellulolytic enzymes are generally clustered on the chromosomes in cellulosome-producing microorganisms (Lynd et al. 2002). The expression of cellulosomal genes is mediated by a set of anti- $\sigma$ factors and their cognate alternative- $\sigma$ factors present in the genome of $C$. thermocellum (Nataf et al. 2010). Anti- $\sigma$ factors are multimodular proteins present with intracellular domain for $\sigma$ factor, transmembrane domain and an extracellular domain having CBM or other sugar-binding modules. The binding of CBM to the substrate triggers a change in the conformation of anti- $\sigma$ factors, thereby releasing the alternative- $\sigma$ factors bound to it. This released alternative- $\sigma$ factor finally initiates the transcription of cellulosomal genes by interacting with RNA polymerase (Nataf et al. 2010).
An equivalent set of alternative and anti- $\sigma$ factors have been reported in Bacteroides thetaiotaomicron and Acidothermus cellulolyticus (Nataf et al. 2010). But till date, very little information has been available about the molecular mechanism of cellulosomal genes in other species and efforts are being made to understand the physiology and expression of these genes in other species for their successful exploitation in biorefineries.

\section{Challenges of cellulosomes}

The current research on biofuel production deals with the technological barriers of economical conversion of lignocellulosic biomass to fermentable sugars. However, the high cost of the enzymes is the driving force for the search of other substitutes for efficient hydrolysis of the complex biomass. Moreover, the production of cellulosomes in native microorganisms is inadequate for industrial-scale support (Stern et al. 2014). The efficient enzymatic hydrolysis is dependent on the set of enzymes on the cellulosome, with the most effective enzyme composition being dependent on the respective substrate (Blouzard et al. 2010; Chundawat et al. 2011). Another obstacle is difficult and costly cultivation of native cellulosome-producing bacteria due to requirement of anaerobic conditions (Lambertz et al. 2014).

In view of this, efforts are being made to artificially construct the cellulosomes to depolymerize the cellulosic substrate to simple fermentable sugars for biofuel production. Moreover, with increase in understanding the physiology and mechanism of gene regulation of cellulosomes, efforts are being made for the expression of cellulosomal complexes in recombinant microorganisms (Nataf et al. 2010). During the past few years, efforts have been made for the construction of "designer cellulosomes", i.e., artificial complexes that could efficiently depolymerize cellulose. The construction of designer cellulosomes is very challenging, but this technology can be efficiently improved and utilized in the biorefineries (Fontes and Gilbert 2010).

\section{Alternative-designer cellulosomes}

The concept of designer cellulosomes was first suggested by Bayer et al. (1994) and the first attempt of construction and utility was accomplished by Fierobe et al. (2001). Designer cellulosomes are artificially constructed complexes of enzymes, generally equipped with a dockerin module that interacts with cohesin module with high specificity and affinity and degrades the polymeric cellulose efficiently (Vazana et al. 2012). The arrangement of different cellulosomal subunits enables controlling the composition and spatial constraints, thereby increasing the efficiency of the whole system (Bayer et al. 2007). Hence, the disruption of the chain in the cellulose is the 
rate-limiting step rather than the cleavage of the glycosidic bond, thereby rendering the substrate easily accessible to enzyme for the hydrolysis.

Designer cellulosomes have been constructed using different approaches such as construction of a shortened scaffoldin with cohesins of corresponding specificity, construction of chimeric scaffoldin with different cohesins and addition of dockerin moieties to enzymes (Ding et al. 2008). Apart from the cellulosomal enzymes, various free enzymes from Thermobifida fusca and Neocallimastix patriciarum can also be exploited for the construction of cellulosomes (Caspi et al. 2008). A CBM domain is constructed on the artificial scaffoldin, which serves as the harboring backbone. The construction and various components of designer cellulosomes are shown in Table 1.

In the design of chimeric scaffoldin, the arrangement of different cohesin subunits and distance between them are maintained by the linker segments (Vazana et al. 2012; Hendrix et al. 2013). The linker regions are accountable for the plasticity and catalytic efficiency of the cellulosomes by enabling the spatial arrangement of the catalytic modules to adjust according to the substrate and allow the enzymes to act synergistically (Garcia-Alvarez et al. 2011; Molinier et al. 2011). The amino acid residues in the linker segments can vary from 5 to 8 residues as in C. cellulolyticum, C. acetobutylicum, C. cellulovorans and $C$. josui to 20-40 residues as in B. cellulosolvens, $R$. flavefaciens, A. cellulolyticus and C. thermocellum (Bayer et al. 2009). Vazana et al. (2013) investigated the spatial organization of the scaffoldin subunit along with their effects on hydrolysis of cellulose by designing trivalent designer scaffoldins with CBM and three divergent cohesin modules and concluded that long intermodular linkers provide better flexibility and spatial positioning of the attached enzyme in the cellulosome complex. Molinier et al. (2011) investigated the association between the conformational flexibility and the inter-modular linkers of scaffold protein of cellulosomes and reported that specific inter-cohesins sequence or distance was not required to induce proximal synergy.

Construction of cohesin domains in the designer cellulosome from various species allows incorporation of the desired dockerin-bearing enzymes, which could interact synergistically with efficient hydrolysis of the complex substrate (Morais et al. 2010; Caspi et al. 2008; Vazana et al. 2010).

Another important aspect in the construction of designer cellulosomes is the surface display of cellulosomal proteins. Anchoring of cellulosomal enzymes on the surface protects them from the proteases and thermal degradation of the host cells (Wieczorek and Martin 2010), which makes such cellulosomes highly desirable in recombinant microbes (Hasunuma and Kondo 2012). Surface display also promotes synergism and specific activity in different enzymes attached due to very close proximity (Schwarz 2001) and reduces the amount of total enzyme added to the bioreactor (Matano et al. 2012a). Moreover, surface display aids in higher yield due to prevention of irreversible desorption of the enzyme from its substrate (Bayer et al. 1994; Schwarz 2001; Matano et al. 2012b; Tanaka and Kondo 2015). The surface-displayed enzymes work synergistically to hydrolyze cellulose to cello-oligosaccharides and then to glucose, which is very close to the cell surface and is immediately taken up by the fermenting microorganism instead of diffusing out into the medium, thereby increasing the yield (Yamada et al. 2013). Since the fermentable sugars released are easily transported inside the cells for subsequent metabolic pathways, the level of glucose in the medium remains low, thereby decreasing the chances of contamination. Several mechanisms for the surface display of protein include covalent interactions with long-chain fatty acids and covalent or non-covalent interactions with the cell wall through linkage to the cell membrane or via transmembrane domains (Desvaux et al. 2009). The microorganisms can also be modified to secrete the cellulosomal components, which cannot be anchored on the cell surface (Fan et al. 2012; Goyal et al. 2011; Kim et al. 2013; Tsai et al. 2009).

However, apart from various advantages, surface display also suffers from few shortcomings. The amount of cellulosomal enzymes to be displayed is dependent on the available surface area (Yamada et al. 2013). Also, the unifunctional surface-displayed cellulosomes are not capable of 2-D diffusion (Tanaka and Kondo 2015). Apart from this, the cohesin-dockerin interactions are species specific, which restricts their utilization over a narrow range. Another problem with the surface-displayed cellulosomes is the effective cellulosomal assembly over the cell surface and higher specific activity of the enzymes.

Keeping in view these weaknesses, many researchers have worked on few modifications in surface-displayed cellulosomes to improve their potential. Wen et al. (Wen et al. 2010) spatially distributed the minicellulosomal complexes on the yeast cell surface for 2-D diffusion and reported an ethanol yield of $0.31 \mathrm{~g} \mathrm{~g}^{-1}$ on phosphoric acid-swollen cellulose (PASC) consumed. To overcome the narrow range of species-specific interactions, a combination ratio of each cell type in the consortium may be optimized, where each cell type displays an effective overall cellulosome assembly in the synthetic consortium. Tsai et al. (2010) optimized the mixing ratio of different populations and constructed a synthetic consortium expressing different components of cellulosomes for the conversion of amorphous (phosphoric 


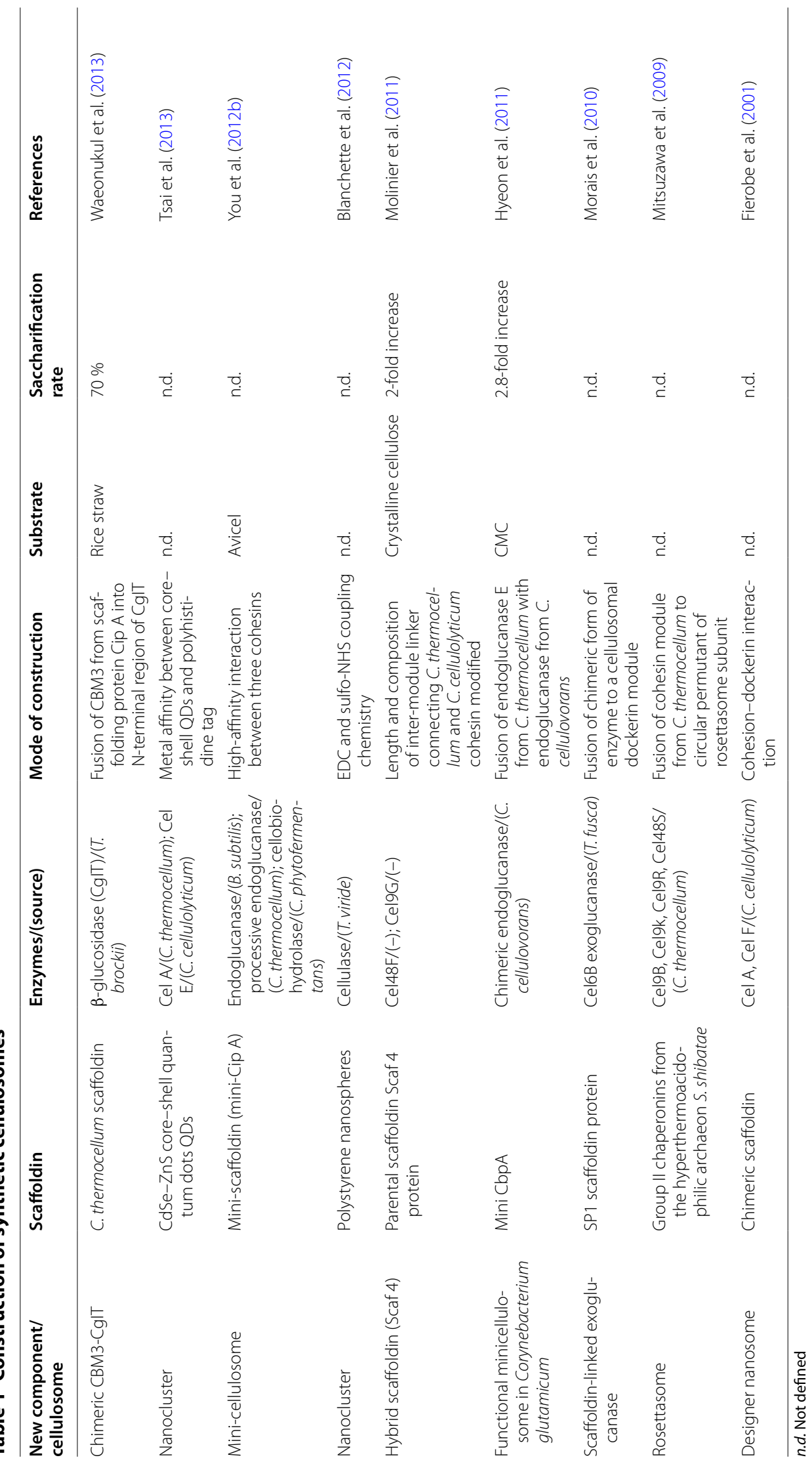


acid-swollen) cellulose to ethanol with $93 \%$ of maximum theoretical yield. A 4.2-fold increase in the hydrolysis of phosphoric acid-swollen cellulose (PASC) was reported with a tetravalent cellulosome expressed on the surface of the yeast cell as compared to the free enzymes (Tsai et al. 2013). Ito et al. (2009) developed recombinant yeast having a designer minicellulosome system displayed on its surface by assembling different components of the cellulosomal system C. cellulovorans, T. reesei and A. aculeatus for the hydrolysis of $\beta$-glucan. Similar studies were reported by Yanase et al. (2010a, b) for the surface display of cellulolytic enzymes in $K$. marxianus on $\beta$-glucan for ethanol production. You et al. (2012a) reported that efficient digestion of low- accessibility cellulose in the pretreated biomass could be raised up to $90 \%$ by constructing synthetic cellulosomes. Further, type I and type II interactions may be exploited for effective cellulosomal assembly. Fan et al. (2012) utilized type I and type II cohesin-dockerin interactions to construct minicellulosomes and mediate the anchoring of cellulosomes onto the cell surface, respectively, which allowed the complete regulation of cellulosome assembly, their attachment to cell surface and insertion of catalytic units. For improvement in the effective cellulosomal assembly and higher specific activity of cellulosomal enzymes, many structural changes in the enzymes have been incorporated. Suzuki et al. (2012) reported deglycosylation of cellulosomal enzymes, which enhances the cellulosomal assembly in $S$. cerevisiae. Matsuoka et al. (2014) reported that deletion of MNN2 increased the surface-displayed beta-glucosidase and endoglucanase activity by 1.6 -fold and 1.9 fold, respectively, than that of the wild-type isolate.

However, synthetic cellulosomes constructed so far are less active than their natural counterparts. Construction of better complexes is required with efficient catalytic activity than the wild cellulosomes. Thus, more efforts are being made to construct broad substrate-range minicellulosomes (Fontes and Gilbert 2010) and multiple scaffoldin units in larger cellulosomes (Fan et al. 2012) for biofuel production at the industrial scale (Alper and Stephanopoulos 2009).

\section{Applications of cellulosomes}

The future of cellulosomics is very immense and bright. Cellulosomes can be applied to various fields including biorefineries, bioadsorption, bioremediation, production of useful chemicals and as biosensors. Cellulosomes can play a major role in the biorefineries for the depolymerization of complex biomass (Nakashima et al. 2011). Goyal et al. (2011) constructed a minicellulosome by developing a yeast consortium for display of scaffolding protein and secretion of dockerin-fused enzymes for efficient bioethanol production. Bioadsorption of rare and essential metal ions like tungstate and molybdate have also been reported for adsorption and resource recovery (Nishitani et al. 2010; Kuroda et al. 2012). Another field of their application is bioremediation, where they are used as pollutant removers (Fukuda et al. 2010; Kuroda and Ueda 2010; Kuroda and Ueda 2011). Degradation of many toxic compounds using decontaminating enzymes fused with cellulose-binding CBMs has been reported, which enabled a single-step purification and immobilization of fusion proteins into different cellulosic materials (Xu et al. 2002). Cellulosomal systems armed on the cell surface can also be utilized for production of various chemicals like ethyl hexanoate (Su et al. 2010), isoflavone aglycones (Kaya et al. 2008), carnosine (Inaba et al. 2010), chitosan and alginate oligosaccharides (Fukuda et al. 2007; Liu et al. 2009).

Based on the highly specific cohesin-dockerin interactions, cellulosomes can be used to develop single or multi-target biosensors (Jeon et al. 2012). Moreover, engineered CBMs fused with antibody-binding domains can be used as biosensors for sensing pathogens, biomarkers and environmental pollutants (Hussack et al. 2009). Another application of engineered CBM is to characterize native and engineered carbohydrate biomaterials by using various fluorescent techniques (Gourlay et al. 2012; Gao et al. 2014). Apart from this, CBMs can serve as attractive affinity tags and, hence, used in the production and purification of antibodies, peptides and enzymes (Hyeon et al. 2011, 2012; Ramos et al. 2010; Wan et al. 2011). Ramos et al. (2013) have reported the production and purification of recombinant antimicrobial peptides in Escherichia coli by using CBM.

Apart from this, many researchers have also reported other applications of cellulosomal enzymes including removal of bacterial biofilms (Juturu and Wu 2014); enhancement of mechanical and physical properties of paper (Cadena et al. 2010; Shi et al. 2014); in textile, detergent and food processing (Juturu and Wu 2014; Karmakar and Ray 2011; Kuhad et al. 2011; Oliveira et al. 2015).

\section{Future prospects}

The utilization of lignocellulosic feedstocks as an alternative to fossil-derived fuels for biofuel production aids in a cleaner and green environment. Construction of better cellulosomal proteins to efficiently hydrolyze cellulose to fermentable sugars for the production of bioethanol is under progress. The recombinant microorganisms with designer cellulosomal enzymes would convert the lignocellulosic biomass to simple sugars in the biorefineries. 


\section{Abbreviations}

CBM: carbohydrate-binding module; LCB: lignocellulosic biomass; NMR: nuclear magnetic resonance; PASC: phosphoric acid swollen cellulose; SLH: surface layer homology.

\section{Authors' contributions}

RA wrote this manuscript. SB and NKS contributed general advice. SK edited the manuscript. All authors read and approved the final manuscript.

\section{Author details}

${ }^{1}$ Biochemical Conversion Division, Sardar Swaran Singh National Institute of Bio-Energy (Formerly Sardar Swaran Singh National Institute of Renewable Energy), Kapurthala, Punjab, India. ${ }^{2}$ I. K. Gujral Punjab Technical University, Kapurthala, Punjab, India.

\section{Acknowledgements}

We thank Prof. Y. K. Yadav, Director General, SSS-NIBE, Kapurthala, for his valuable suggestions and encouragement to carry out this work. We greatly acknowledge the Ministry of New and Renewable Energy, Government of India, for providing funds to carry out research. One of the authors (Richa Arora) also acknowledges I. K. Gujral Punjab Technical University, Kapurthala, for her Ph.D. registration.

\section{Compliance with ethical guidelines}

\section{Competing interests}

The authors declare that they have no competing interests.

Received: 13 May 2015 Accepted: 12 August 2015

Published online: 25 August 2015

\section{References}

Adams JJ, Webb BA, Spencer HL, Smith SP (2005) Structural characterization of the type II dockerin module from the cellulosome of Clostridium thermocellum: calcium-induced effects on conformation and target recognition. Biochemistry 44:2173-2182

Alper H, Stephanopoulos G (2009) Engineering for biofuels: exploiting innate microbial capacity or importing biosynthetic potential? Nat Rev Micro biol 7:715-723

Anbar M, Gul O, Lamed R, Sezerman UO, Bayer EA (2012) Improved thermostability of Clostridium thermocellum endoglucanase Cel8A using consensus-guided mutagenesis. Appl Environ Microbiol 287:9213-9221

Arora R, Behera S, Sharma NK, Singh R, Yadav YK, Kumar S (2014) Biochemical conversion of rice straw (Oryza sativa L.) to bioethanol using thermotolerant isolate K. marxianus NIRE-K3. In: Sharma NR, Thakur RC, Sharma M, Parihar L, Kumar G (eds) Proceedings of exploring and basic sciences for Next Generation Frontiers. Elsevier, New Delhi, pp 143-146

Arora R, Behera S, Kumar S (2015) Bioprospecting thermophilic/thermotolerant microbes for production of lignocellulosic ethanol: A future perspective. Renew Sust Energy Rev 51:699-717

Bayer EA, Morag E, Lamed R (1994) The cellulosome: a treasure-trove for biotechnology. Trends Biotechnol 12:379-386

Bayer EA, Belaich JP, Shoham Y, Lamed R (2004) The cellulosomes: multienzyme machines for degradation of plant cell wall polysaccharides. Annu Rev Microbiol 58:521-554

Bayer EA, Lamed R, Himmel ME (2007) The potential of cellulases and cellulosomes for cellulosic waste management. Curr Opin Biotechnol 18:237-245

Bayer EA, Lamed R, White BA, Flint HJ (2008) From cellulosomes to cellulosomics. Chem Rec 8:364-377

Bayer EA, Smith SP, Noach I, Alber O, Adams JJ, Lamed R, Shimon LW, Frolow F (2009) Can we crystallize a cellulosome? In: Karita S, Kimura T, Sakka M, Matsui H, Miyake H, Tanaka A, Sakka K (eds) Biotechnology of lignocellulose degradation and biomass utilization. Ito Print Publishing, Tokyo, pp 183-205

Behera S, Arora R, Kumar S (2013) Bioprospecting the cellulases and xylanases thermozymes for the production of biofuels. In: Paper presented at AICHE Annual Meeting, San Francisco, 3-8 November, 2013
Behera S, Arora R, Nandhagopal N, Kumar S (2014) Importance of chemical pretreatment for bioconversion of lignocellulosic biomass. Renew Sust Energy Rev 36:91-106

Belaich JP, Tardif C, Belaich A, Gaudin C (1997) The cellulolytic system of Clostridium cehlolyticum. J Biotechnol 57:3-14

Blanchette C, Lacayo Cl, Fischer NO, Hwang M, Thelen MP (2012) Enhanced cellulose degradation using cellulase-nanosphere complexes. PLoS One 7:e42116

Blouzard JC, Coutinho PM, Fierobe HP, Henrissat B, Lignon S, Tardif C, Pages S, de Philip P (2010) Modulation of cellulosome composition in Clostridium cellulolyticum: adaptation to the polysaccharide environment revealed by proteomic and carbohydrate-active enzyme analyses. Proteomics 10:541-554

Bomble YJ, Beckham GT, Matthews JF, Nimlos MR, Himmel ME, Crowley MF (2011) Modeling the self-assembly of the cellulosome enzyme complex. J Biol Chem 286:5614-5623

Boraston AB, Bolam DN, Gilbert HJ, Davies GJ (2004) Carbohydrate-binding modules: fine-tuning polysaccharide recognition. Biochem J 382:769-781

Bras JLA, Carvalhi AL, Viegas A, Najmudin S, Alves VD, Prates JAM, Ferreira LMA, Romao MJ, Gilbert HJ, Fontes CMGA (2012) Escherichia coli expression, purification, crystallization, and structure determination of bacterial cohesin-dockerin complexes. Methods Enzymol 510:395-415

Cadena EM, Chriac Al, Pastor FI, Diaz P, Vidal T, Torres AL (2010) Use of cellulases and recombinant cellulose binding domains for refining TCF kraft pulp. Biotechnol Prog 26:960-967

Caspi J, Irwin D, Lamed R, Li Y, Fierobe HP, Wilson DB, Bayer EA (2008) Conversion of Thermobifida fusca free exoglucanases into cellulosomal components: comparative impact on cellulose-degrading activity. J Biotechnol 135:351-357

Chanal A, Mingardon F, Bauzan M, Tardif C, Fierobe HP (2011) Scaffoldin modules can serve as "cargo" domains to promote the secretion of heterologous cellulosomal cellulases by Clostridium acetobutylicum. Appl Environ Microbiol 77:6277-6280

Chen C, Cui Z, Xiao Y, Cui Q, Smith SP, Lamed R, Bayer EA, Feng Y (2014) Revisiting the NMR solution structure of the Cel48S type-I dockerin module from Clostridium thermocellum reveals a cohesin-primed conformation. J Struct Biol 188:188-193

Cho W, Jeon SD, Shim HJ, Doi RH, Han SO (2010) Cellulosomic profiling produced by Clostridium cellulovorans during growth on different carbon sources explored by the cohesin marker. J Biotechnol 145:233-239

Chundawat SPS, Beckham GT, Himmel ME, Dale BE (2011) Deconstruction of lignocellulosic biomass to fuels and chemicals. Annu Rev Chem Biomol Eng 2:121-145

Desvaux M (2005) Clostridium cellulolyticum model organism of mesophilic celIulolytic clostridia. FEMS Microbiol Rev 29:741-764

Desvaux M, Dumas E, Chafsey I, Hebraud M (2006) Protein cell surface display in Gram-positive bacteria: from single protein to macromolecular protein structure. FEMS Microbiol Lett 256:1-15

Desvaux M, Hebraud M, Taylor R, Henderson IR (2009) Secretion and subcelIular localizations of bacterial proteins: a semantic awareness issue. Trends Microbiol 17:139-145

Ding SY, Xu Q, Crowley M, Zeng Y, Nimlos M, Lamed R, Bayer EA, Himmel ME (2008) A biophysical perspective on the cellulosome: new opportunities for biomass conversion. Curr Opin Biotechnol 19:218-227

Ding SY, Liu Y-S, Zeng Y, Himmel ME, Baker JO, Bayer EA (2012) How does plant cell wall nanoscale architecture correlate with enzymatic digestibility? Science 338:1055-1060

Doi RH (2008) Cellulases of mesophilic microorganisms: cellulosome and noncellulosome producers. Ann N Y Acad Sci 1125:267-279

Doi RH, Kosugi A (2004) Cellulosomes: plant cell wall degrading enzyme complexes. Nat Rev (Microbiol) 2:541-551

Elkins JG, Raman B, Keller M (2010) Engineered microbial systems for enhanced conversion of lignocellulosic biomass. Curr Opin Biotechno 21:657-662

Fan LH, Zhang ZJ, Yu XY, Xue YX, Tan TW (2012) Self-surface assembly of cellulosomes with two miniscaffoldins on Saccharomyces cerevisiae for cellulosic ethanol production. Proc Natl Acad Sci USA 109:13260-13265

Fierobe H-P, Mechaly A, Tardif C, Belaich A, Lamed R, Shoham Y, Belaich JP, Bayer EA (2001) Design and production of active cellulosome chimeras: 
selective incorporation of dockerin-containing enzymes into defined functional complexes. J Biol Chem 276:21257-21261

Fierobe HP, Mingardon F, Mechaly A, Belaich A, Rincon MT, Pages S, Lamed R, Tardif C, Belaich JP, Bayer EA (2005) Action of designer cellulosomes on homogeneous versus complex substrates: controlled incorporation of three distinct enzymes into a defined trifunctional scaffoldin. J Biol Chem 280:16325-16334

Fontes C, Gilbert HJ (2010) Cellulosomes: highly efficient nanomachines designed to deconstruct plant cell wall complex carbohydrates. Annu Rev Biochem 79:655-681

Fukuda T, Isogawa D, Takagi M, Kato-Murai M, Kimoto H, Kusaoke H, Ueda M, Suye S (2007) Yeast cell-surface expression of chitosanase from Paenibacillus fukuinensis. Biosci Biotechnol Biochem 71:2845-2847

Fukuda T, Tsuchiyama K, Makishima H, Takayama K, Mulchandani A, Kuroda K, Ueda M, Suye S (2010) Improvement in organophosphorus hydrolase activity of cell surface-engineered yeast strain using Flo1p anchor system. Biotechnol Lett 32:655-659

Gao SH, You C, Renneckar S, Bao J, Zhang YHP (2014) New insights into enzymatic hydrolysis of heterogeneous cellulose by using carbohydratebinding module 3 containing GFP and carbohydrate-binding module 17 containing CFP. Biotechnol Biofuels 7:24

Garcia-Alvarez B, Melero R, Dias FM, Prates JA, Fontes CM, Smith SP, Romao MJ, Carvalho AL, Llotca O (2011) Molecular architecture and structural transitions of a CLostridium thermocellum mini-cellulosome. J Mol Biol 407:571-580

Garvey M, Klose H, Fischer R, Lambertz C, Commandeur U (2013) Cellulases for biomass degradation: comparing recombinant cellulose expression platforms. Trends Biotechnol 31:581-593

Gefen G, Anbar M, Morag E, Lamed R, Bayer EA (2012) Enhanced cellulose degradation by targeted integration of a cohesin-fused $\beta$-glucosidase into the Clostridium thermocellum cellulosome. Proc Natl Acad Sci USA 109:10298-10303

Gourlay K, Arantes V, Saddler JN (2012) Use of substructure-specific carbohydrate binding modules to track changes in cellulose accessibility and surface morphology during the amorphogenesis step of enzymatic hydrolysis. Biotechnol Biofuels 5:51

Goyal G, Tsai S-L, Madan B, DaSilva NA, Chen W (2011) Simultaneous cell growth and ethanol production from cellulose by an engineered yeast consortium displaying a functional mini-cellulosome. Microb Cell Fact 10:89

Hasunuma T, Kondo A (2012) Development of yeast cell factories for consolidated bioprocessing of lignocelluloses to bioethanol through cell surface engineering. Biotechnol Adv 30:1207-1218

Hemme CL, Mouttaki H, Lee YJ, Zhang G, Goodwin L, Lucas S, Copeland A, Lapidus A, Glavina del Rio T, Tice H, Saunders E, Brettin T, Detter JC, Han CS, Pitlick S, Land ML, Hauser LJ, Kyrpides N, Mikhailova N, He Z, Wu L, Van Nostrand JD, Henrissat B, He Q, Lawson PA, Tanner RS, Lynd LR, Wiegel J, Fields MW, Arkin AP, Schadt CW, Stevenson BS, Mclnerney MJ, Yang Y, Dong H, Xing D, Ren N, Wang A, Huhnke RL, Mielenz JR, Ding SY, Himmel ME, Taghavi S, van der Lelie D, Rubin EM, Zhou J (2010) Sequencing of multiple clostridial genomes related to biomass conversion and biofuel production. J Bacteriol 192:6494-6496

Hendrix J, Fried D, Barak Y, Bayer EA, Lamb DC (2013) Conformational dynamics in designer cellulosomes studied by single-pair fret with Mfd-Pie. Biophys J 104:19a

Himmel ME, Xu Q, Luo Y, Ding SY, Lamed R, Bayer EA (2010) Microbial enzyme systems for biomass conversion: emerging paradigms. Biofuels 1:323-341

Horn JH, Vaaje-Kolstad G, Westereng B, Eijsink VGH (2012) Novel enzymes for the degradation of cellulose. Biotechnol Biofuels 5:1-12

Hussack G, Luo Y, Veldhuis L, Hall JC, Tanha J, Mackenzie R (2009) Multivalent anchoring and oriented display of single-domain antibodies on cellulose. Sensors 9:5351-5367

Hyeon JE, Jeon WJ, Whang SY, Han SO (2011) Production of minicellulosomes for the enhanced hydrolysis of cellulosic substrates by recombinant Corynebacterium glutamicum. Enzyme Microb Technol 48:371-377

Hyeon JE, Kang DH, Kim YI, Jeon SD, You SK, Kim KY, Kim SW, Han SO (2012) Production of functional agarolytic nano-complex for the synergistic hydrolysis of marine biomass and its potential application in carbohydrate-binding module-utilizing one-step purification. Process Biochem 47:877-881
Hyeon JE, Jeon SD, Han SO (2013) Cellulosome-based, Clostridium-derived multi-functional enzyme complexes for advanced biotechnology tool development: advances and applications. Biotechnol Adv 31:936-944

Ichikawa S, Karita S, Kondo M, Goto M (2014) Cellulosomal carbohydrate-binding module from Clostridium josui binds to crystalline and non-crystalline cellulose, and soluble polysaccharides. FEBS Lett 588:3886-3890

Inaba C, Higuchi S, Morisaka H, Kuroda K, Ueda M (2010) Synthesis of functional dipeptide carnosine from nonprotected amino acids using carnosinasedisplaying yeast cells. Appl Microbiol Biotechnol 86:1895-1902

Ito J, Kosugi A, Tanaka T, Kuroda K, Shibasaki S, Ogino C, Ueda M, Fukuda H, Dsoi $\mathrm{RH}$, Kondo A (2009) Regulation of the display ratio of enzymes on the Sacchromyces cerevisiae cell surface by the immunoglobulin $\mathrm{G}$ and cellulosomal enzyme binding domains. Appl Environ Microbiol 75:4149-4154

Jeon SD, Lee JE, Kim SJ, Kim SW, Han SO (2012) Analysis of selective, high protein-protein binding interaction of cohesin-dockerin complex using biosensing methods. Biosens Bioelectron 35:382-389

Ju LK, Afolabi OA (1999) Wastepaper hydrolysate as soluble inducing substrate for cellulase production in continuous culture of Trichoderma reesei. Biotechnol Prog 15:91-97

Juturu V, Wu JC (2014) Microbial cellulases: Engineering, production and applications. Renew Sust Energy Rev 33:188-203

Karmakar M, Ray RR (2011) Current trends in research and application of microbial cellulases. Res J Microbiol 6:41-53

Karpol A, Jobby MK, Slutzki M, Noach I, Chitayat S, Smith SP, Bayer EA (2013) Structural and functional characterization of a novel type-III dockerin from Ruminococcus flavefaciens. FEBS Lett 587:30-36

Kaya M, Ito J, Kotaka A, Matsumura K, Bando H, Sahara H, Ogino C, Shibasaki S, Kuroda K, Ueda M, Kondo A, Hata Y (2008) Isoflavone aglycones production from isoflavone glycosides by display of $\beta$-glucosidase from Aspergillus oryzae on yeast cell surface. Appl Microbiol Biotechnol 79:51-60

Kim S, Baek S-H, Lee K, Hahn J-S (2013) Cellulosic ethanol production using a yeast consortium displaying a minicellulosome and beta-glucosidase. Microb Cell Fact 12:14

Koukiekolo R, Cho HY, Kosugi A, Inui M, Yukawa H, Doi RH (2005) Degradation of corn fiber by Clostridium cellulovorans cellulases and hemicellulases and contribution of scaffolding protein CbpA. Appl Environ Microbiol 71:3504-3511

Krauss J, Zverlov W, Schwarz WH (2012) In vitro reconstitution of the complete Clostridium thermocellum cellulosome and synergistic activity on crystalline cellulose. Appl Environ Microbiol 78:4301-4307

Kuhad RC, Gupta R, Singh A (2011) Microbial cellulases and their industrial applications. Enzyme Res 2011:1-10

Kumar R, Singh S, Singh OV (2008) Bioconversion of lignocellulosic biomass: biochemical and molecular perspectives. J Ind Microbiol Biotechnol 35:377-391

Kumar S, Singh SP, Mishra IM, Adhikari DK (2010) Feasibility of ethanol production with enhanced sugar concentration in bagasse hydrolysate at high temperature using Kluyveromyces sp. IIPE453. Biofuels 1:697-704

Kuroda K, Ueda M (2010) Engineering of microorganisms towards recovery of rare metal ions. Appl Microbiol Biotechnol 87:53-60

Kuroda K, Ueda M (2011) Molecular design of the microbial cell surface toward the recovery of metal ions. Curr Opin Biotechnol 22:427-433

Kuroda K, Nishitani T, Ueda M (2012) Specific adsorption of tungstate by cell surface display of the newly designed ModE mutant. Appl Microbiol Biotechnol 96:153-159

Lambertz C, Garvey M, Klinger J, Hessel D, Klose H, Fischer R, Commandeur $U$ (2014) Challenges and advances in the heterologous expression of cellulolytic enzymes: a review. Biotechnol Biofuels 7:135

Lamed R, Setter E, Bayer EA (1983) Characterization of a cellulose-binding, cellulase-containing complex in Clostridium thermocellum. J Bacteriol 156:828-836

Lavan LM, Van Dyk JS, Chan H, Dsoi RH, Pletschke BI (2009) Effect of physical conditions and chemicals on the binding of a mini-CbpA from Clostridium cellulovorans to a semi-crystalline cellulose ligand. Lett Appl Microbiol 48:419-425

Li D-C, Li A-N, Papageorgiou AC (2011) Cellulases from thermophilic fungi: recent insights and biotechnological potential. Enzyme Res 2011:308730

Liu G, Yue L, Chi Z, Yu W, Chi Z, Madzak C (2009) The surface display of the alginate lyase on the cells of Yarrowia lipolytica for hydrolysis of alginate. Mar Biotechnol (NY) 11:619-626 
Lynd LR, Weimer PJ, van ZyI WH, Pretorius IS (2002) Microbial cellulose utilization: fundamentals and biotechnology. Microbiol Mol Biol Rev 66:506-577

Matano Y, Hasunuma T, Kondo A (2012a) Simultaneous improvement of saccharification and ethanol production from crystalline cellulose by alleviation of irreversible adsorption of cellulose with a cell surfaceengineered yeast strain. Appl Microbiol Biotechnol 97:2231-2237

Matano Y, Hasunuma T, Kondo A (2012b) Display of cellulases on the cell surface of Saccharomyces cerevisiae for high yield ethanol production from high-solid lignocellulosic biomass. Bioresour Technol 108:128-133

Matsuoka H, Hashimoto K, Saijo A, Takada Y, Kondo A, Ueda M, Ooshima H, Tachibana T, Azuma M (2014) Cell wall structure suitable for surface display of proteins in Saccharomyces cerevisiae. Yeast 31:67-76

Mazzoli R (2012) Development of microorganisms for cellulose-biofuel consolidated bioprocessings: metabolic engineers tricks. Comput Struct Biotechnol J 3:1-9

Mazzoli R, Lamberti C, Pessione E (2012) Engineering new metabolic capabilities in bacteria: lessons from recombinant cellulolytic strategies. Trends Biotechnol 30:111-119

Mitsuzawa S, Kagawa H, Li Y, Chan SL, Paavola CD, Trent JD (2009) The rosettazyme: a synthetic cellulosome. J Biotechnol 143:139-144

Molinier AL, Nouailler M, Valette O, Tardif C, Receveur-Brechot V, Fierobe HP (2011) Synergy, structure and conformational flexibility of hybrid cellulosomes displaying various inter-cohesins linkers. J Mol Biol 405:143-157

Morais S, Barak Y, Caspi J, Hadar Y, Lamed R, Shoham Y, Wilson DB, Bayer EA (2010) Cellulase-xylanase synergy in designer cellulosomes for enhanced degradation of a complex cellulosic substrate. MBio 1:e00285-e00310

Nakashima K, Yamaguchi K, Taniguchi N, Arai S, Yamada R, Katahira S, Ishida N, Takahashi H, Ogino C, Kondo A (2011) Direct bioethanol production from cellulose by the combination of cellulase-displaying yeast and ionic liquid pretreatment. Green Chem 13:2948-2953

Nataf Y, Bahari L, Kahel-Raifer H, Borovok I, Lamed R, Bayer EA, Sonenshein AL, Shoham Y (2010) Clostridium thermocellum cellulosomal genes are regulated by extracytoplasmic polysaccharides via alternative sigma factors. Proc Natl Acad Sci USA 107:18646-18651

Nishitani T, Shimada M, Kuroda K, Ueda M (2010) Molecular design of yeast cell surface for adsorption and recovery of molybdenum, one of rare metals. Appl Microbiol Biotechnol 86:641-648

Oliveira C, Carvalho V, Domingues L, Gama FM (2015) Recombinant CBM-fusion technology-applications overview. Biotechnol Adv 33:358-369

Prasetyo J, Naruse K, Kato T, Boonchird C, Harashima S, Park EY (2011) Bioconversion of paper sludge to biofuel by simultaneous saccharification and fermentation using a cellulase of paper sludge origin and thermotolerant Saccharomyces cerevisiae TJ14. Biotechnol Biofuels 4:35

Raman B, Pan C, Hurst GB, Rodriguez JM, McKeown CK, Lankford PK, Samatova NF, Mielenz JR (2009) Impact of pretreated switchgrass and biomass carbohydrates on Clostridium thermocellum ATCC 27405 cellulosome composition: a quantitative proteomic analysis. PLoS One 4:e5271

Ramos R, Domingues L, Gama M (2010) Escherichia coli expression and purification of LL37 fused to a family III carbohydrate-binding module from Clostridium thermocellum. Protein Expr Purif 71:1-7

Ramos R, Moreira S, Rodrigues A, Gama M, Domingues L (2013) Recombinant expression and purification of the antimicrobial peptide magainin-2. Biotechnol Prog 29:17-22

Rollin JA, Zhu Z, Sathisuksanoh N, Zhang HP (2011) Increasing cellulose accessibility is more important than removing lignin: a comparison of cellulose solvent-based lignocellulose fractionation and soaking in aqueous ammonia. Biotechnol Bioeng 108:22-30

Sadhu S, Maiti TK (2013) Cellulase production by bacteria: a review. British Microbiol Res J 3:235-258

Schwarz WH (2001) The cellulosome and cellulose degradation by anaerobic bacteria. Appl Microbiol Biotechnol 56:634-649

Shahriarinour M, Wahab MNA, Mohamad R, Mustafa S, Ariff AB (2011) Effect of medium composition and cultural condition on cellulase production by Aspergillus terreus. Afr J Biotechnol 10:7459-7467

Shi X, Zheng F, Pan R, Wang J, Ding S (2014) Engineering and comparative characteristics of double carbohydrate binding modules as a strength additive for papermaking applications. Bioresources 9:3117-3131
Shoham Y, Lamed R, Bayer EA (1999) The cellulosome concept as an efficient microbial strategy for the degradation of insoluble polysaccharides. Trends Microbiol 275:275-281

Smith SP, Bayer EA (2013) Insights into cellulosome assembly and dynamics: from dissection to reconstruction of the supramolecular enzyme complex. Curr Opin Struct Biol 23:686-694

Stern J, Anbar M, Morais S, Lamed R, Bayer EA (2014) Insights into enhanced thermostability of a cellulosomal enzyme. Carbohyd Res 389:78-84

Su GD, Huang DF, Han SY, Zheng SP, Lin Y (2010) Display of Candida antarctica lipase B on Pichia pastoris and its application to flavor ester synthesis. Appl Microbiol Biotechnol 86:1493-1501

Sukumaran RK, Singhania RR, Pandey A (2005) Microbial cellulases: production, application and challenges. J Sci Ind Res 64:832-844

Suzuki H, Imaedaa T, Kitagawa T, Kohda K (2012) Deglycosylation of cellulosomal enzyme enhances cellulosome assembly in Saccharomyces cerevisiae. J Biotechnol 157:64-70

Tamaru Y, Karita S, Ibrahim A, Chan H, Dsoi RH (2000) A large gene cluster for the Clostridium cellulovorans cellulosome. J Bacteriol 182:5906-5910

Tamaru Y, Miyake H, Kuroda K, Ueda M, Doi RH (2010) Comparative genomics of the mesophilic cellulosome-producing Clostridium cellulovorans and its application to biofuel production via consolidated bioprocessing. Environ Technol 31:889-903

Tanaka T, Kondo A (2015) Cell surface engineering of industrial microorganisms for biorefining applications. Biotechnol Adv (in press)

Taylor TJ, Vaisman II (2010) Discrimination of thermophilic and mesophilic proteins. BMC Struct Biol 10:S5

Tsai SL, Oh J, Singh S, Chen R, Chen W (2009) Functional assembly of minicellulosomes on the Saccharomyces cerevisiae cell surface for cellulose hydrolysis and ethanol production. Appl Environ Microbiol 75:6087-6093

Tsai SL, Goyal G, Chen W (2010) Surface display of a functional minicellulosome by intracellular complementation using a synthetic yeast consortium and its application to cellulose hydrolysis and ethanol production. Appl Environ Microbiol 76:7514-7520

Tsai SL, DaSilva NA, Chen W (2013) Functional display of complex cellulosomes on the yeast surface via adaptive assembly. ACS Synth Biol 2:14-21

Vazana Y, Morais S, Barak Y, Lamed R, Bayer EA (2010) Interplay between Clostridium thermocellum family 48 and family 9 cellulases in cellulosomal versus noncellulosomal states. Appl Environ Microbiol 76:3236-3243

Vazana Y, Morai S, Barak Y, Lamed R, Bayer EA (2012) Designer cellulosomes for enhanced hydrolysis of cellulosic substrates. Methods Enzymol 510:429-452

Vazana Y, Barak Y, Unger T, Peleg Y, Shamshoum M, Ben-Yehezkel T, Mazor Y, Shapiro E, Lamed R, Bayer EA (2013) A synthetic biology approach for evaluating the functional contribution of designer cellulosome components to deconstruction of cellulosic substrates. Biotechnol Biofuels 6:182

Vodovnik M, Logar RM (2010) Cellulosomes-promising supramolecular machines of anaerobic cellulolytic microorganisms. Acta Chim Slov 57:767-774

Waeonukul R, Kosugi A, Prawitwong P, Deng L, Tachaapaikoon C, Pason P, Ratanakhanokchai K, Saito M, Mori Y (2013) Novel cellulase recycling method using a combination of Clostridium thermocellum cellulosomes and Thermoanaerobacter brockii $\beta$-glucosidase. Bioresour Technol 130:424-430

Wan W, Wang D, Gao X, Hong J (2011) Expression of family 3 cellulose-binding module (CBM3) as an affinity tag for recombinant proteins in yeast. Appl Microbiol Biotechnol 91:789-798

Wen F, Sun J, Zhao H (2010) Yeast surface display of trifunctional minicellulosomes for simultaneous saccharification and fermentation of cellulose to ethanol. Appl Environ Microbiol 76:1251-1260

Wieczorek AS, Martin VJ (2010) Engineering the cell surface display of cohesins for assembly of cellulosome-inspired enzyme complexes on Lactococcus lactis. Microb Cell Fact 9:69

Wilson DB (2011) Microbial diversity of cellulose hydrolysis. Curr Opin Microbiol 14:259-263

Wu I, Arnold FH (2013) Engineered thermostable fungal Cel6A and Cel7A cellobiohydrolases hydrolyze cellulose efficiently at elevated temperatures. Biotechnol Bioeng 110:1874-1883 
Xu Z, Bae W, Mulchandani A, Mehra RK, Chen W (2002) Heavy metal removal by novel CBD-EC20 sorbents immobilized on cellulose. Biomacromolecules 3:462-465

Yamada R, Hasunuma T, Kondo A (2013) Endowing non-cellulolytic microorganisms with cellulolytic activity aiming for consolidated bioprocessing. Biotechnol Adv 31:754-763

Yanase S, Hasunuma T, Yamada R, Tanaka T, Ogino C, Fukuda H, Kondo A (2010a) Direct ethanol production from cellulosic materials at high temperature using the thermotolerant yeast Kluyveromyces marxianus displaying cellulolytic enzymes. Appl Microbiol Biotechnol 88:381-388

Yanase S, Yamada R, Kaneko S, Noda H, Hasunuma T, Tanaka T, Ogino C, Fukuda $\mathrm{H}$, Kondo A (2010b) Ethanol production from cellulosic materials using cellulase-expressing yeast. Biotechnol J 5:449-455
Yaniv O, Jindou S, Frolow F, Lamed R, Bayer EA (2012) A simple method for determining specificity of carbohydrate-binding modules for purified and crude insoluble polysaccharide substrates. Methods Mol Biol 908:101-107

You C, Zhang XZ, Sathitsuksanoh N, Lynd LR, Zhang YH (2012a) Enhanced microbial utilization of recalcitrant cellulose by an exvivo cellulosomemicrobe complex. Appl Environ Microbiol 78:1437-1444

You C, Zhang XZ, Zhang YHP (2012b) Mini-scaffoldin enhanced mini-cellulosome hydrolysis performance on low-accessibility cellulose (Avicel) more than on high-accessibility amorphous cellulose. Biochem Eng J 63:57-65

\section{Submit your manuscript to a SpringerOpen ${ }^{\odot}$ journal and benefit from:}

- Convenient online submission

- Rigorous peer review

- Immediate publication on acceptance

- Open access: articles freely available online

- High visibility within the field

- Retaining the copyright to your article

Submit your next manuscript at $>$ springeropen.com 